\title{
COMPUTERISED INFORMATION SYSTEMS: COMPARISON OF RELATIVE IMPACTS ON PLANNED PROJECT DURATION WITHIN A MULTI-PROJECT ENVIRONMENT
}

\author{
S. Govender ${ }^{1}$ and H. Steyn ${ }^{2}$ \\ ${ }^{2}$ Department of Engineering and Technology Management \\ University of Pretoria, South Africa \\ herman.steyn@up.ac.za
}

\begin{abstract}
As more organisations acquire project management computerised information systems (CIS) to ensure the efficient scheduling of projects, there is increasing interest in the extent to which various CIS contribute to a reduction in planned project duration. However, there seems to be no empirical research that suggests that CIS have a positive impact on planned duration or how relative impacts could vary when different CIS are implemented. This paper reports on experimental research that evaluates and draws comparisons between the relative impacts of three CIS on planned project delivery within a specific, real, multi-project environment, and investigates the reasons for such variations.

\section{OPSOMMING}

Namate meer organisasies gerekenariseerde inligtingstelsels bekom om doelmatige skedulering van projekte te verseker, neem belangstelling toe oor die mate waartoe verskillende stelsels bydra tot die verkorting van die beplande tydsduur van projekte. Dit blyk egter dat geen empiriese inligting bestaan wat aandui dat hierdie rekenaarstelsels 'n positiewe impak op beplande duur van projekte het of hoe die impak varieer met die gebruik van verskillende stelsels nie. Hierdie artikel rapporteer oor empiriese navorsing wat die relatiewe impak van drie rekenaarstelsels op beplande projek aflewering in 'n spesifieke, werklike multi-projek omgewing evalueer. Die redes vir die verskille wat gerapporteer word, word ook ondersoek.
\end{abstract}

\footnotetext{
${ }^{1}$ The author was enrolled for the MPM programme at the Department of Engineering and Technology Management, University of Pretoria
} 


\section{INTRODUCTION}

Various computerised information systems (CIS) are used to schedule and track both single and multiple projects. For project-driven organisations to be successful in the exploitation of their strategic initiatives, an appropriate understanding of the impact of CIS on project delivery in multi-project environments is essential. Furthermore, organisations need to ensure that their planned and actual project delivery is consistent with corporate ambitions, and that the processes, techniques, technologies, and resources align with and support the business objectives.

\subsection{Background}

In the current business environment, reduced project duration provides a significant competitive edge. Jugdev and Thomas [7] support this notion by mentioning that because investments are time, cost, and resource intensive - organisations are willing to take a critical interest in those practices that will improve their competitive positions. Reduced project durations may lead to an earlier realisation of cost savings and the seizure of a window of opportunity. It is imperative, therefore, that project-driven organisations ensure adequate attention is paid to the selection of tools to provide the most efficient and effective delivery of projects. Practitioners often assume that project management CIS provide the capability to plan and schedule projects efficiently, and that the power of the personal computer overcomes the complexity of various scheduling techniques. Considering the vast number of continuously evolving CIS currently available at competitive prices, additional attention is required to evaluate and compare such CIS, in an effort to ensure that organisations implement the most appropriate solutions to enable optimal completion of projects, and in turn, achievement of company objectives.

\subsection{Potential benefits of reduced project duration}

It is widely accepted that, in most cases, reduced project durations may offer a variety of benefits to project-driven organisations. An exception to this is cost-plus contracts where finishing early may not be beneficial for the contracted company. Steyn [11] explains that the speed of project execution is becoming increasingly important to ensure the competitiveness of companies. In the current business environment, time-to-market plays a significant role in giving a company the competitive edge within a specific industry. Steyn [11] also emphasises that not only project duration, but also a reliable prediction of the completion date, is essential for success, and that approaches that enable duration compression without increasing business risk would provide several benefits. Regnier [9] supports these views by mentioning that the risk of failing to complete activities on time is a critical element of project management. In addition to cost savings and seizing a window of opportunity, according to Levine [8], the results of reduced project duration could ensure a reduction of period costs, improved cash flow, earlier generation of revenue, better positioning to realise higher profits, and the flexibility to position resources for other work. When such alignment between reduced project duration and the business strategy is clearly established, planned project delivery moves in directions that hold promise for competitive advantage. 


\subsection{Scheduling with project management computerised information systems (CIS)}

Numerous techniques are used in industry to plan, represent, and track the interrelated activities of projects. It is well known that a critical aspect of project management is to schedule a series of inter-related activities to ensure successful project delivery. Scheduling techniques vary in complexity, and may therefore result in excessive time consumption, whilst also being open to human error. In a comparison of manual and computerised scheduling techniques, the inference is that computerised scheduling techniques are far less time consuming than manual methods. Computer systems provide the capability to process information fast, and are useful in doing calculations such as forward pass and backward pass, in order to determine the critical path and float. These capabilities are also useful in performing calculations such as stochastic PERT, time-cost tradeoffs, and simulation of schedules and risks. However, current computer systems are not yet useful in assisting with 'softer' issues such as scope definition, identification of stakeholders, and issues relating to the management of people. Fox and Spence [6] mention that software itself does not make project managers more effective, but it is capable of making them more efficient. It is therefore important to note that project management CIS do not guarantee adequately defined scope, communication to the project committee, or clear assignments to the project team. However, CIS allow a project manager to accomplish these and many other essential project management tasks more efficiently.

\subsection{Research problem}

Section 1.2 highlights the advantages of reduced project duration, while Section 1.3 indicates that CIS can provide organisations with the tools to plan and schedule projects efficiently. However, the extent to which different CIS can contribute to the reduction in project duration requires attention. A literature search suggested that there is limited literature to enable organisations to make an informed decision with regard to the use and effectiveness of project management CIS and their relative impacts on planned project duration within multi-project environments. An investigation into the nature and extent of variations between the scheduling techniques of such packages is therefore imperative. The associated research questions are as follows:

What are the relationships between the project management CIS used and the planned duration of projects in multi-project environments?

What are the differences in scheduling techniques used by the various project management CIS?

What relationships exist between the scheduling techniques applied by CIS and proven project management scheduling methodologies?

By addressing the research questions, the objective of this paper is to identify and draw comparisons between the relative impacts that CIS have on planned project delivery within a specific multi-project environment, and to investigate the reasons for such variations. This includes determining planned duration of individual projects and a combination of projects. The research focuses on the various 
scheduling techniques used by each of three selected CIS, and attempts to draw relationships between the application of these techniques, proven project management methodologies, and the planned duration of multiple projects.

Furthermore, the study attempts to deduce from the schedules how the CIS function and what heuristics they employ. It must, however, be noted that proving the main claims of traditional project management methodologies is not an objective of this study.

In order to address the research problem effectively, this study proposes that:

The identification of appropriate relationships between the CIS and planned project durations within multi-project environments is possible. These specific relationships can be attributed to the various CIS-specific criteria and scheduling techniques used.

These techniques are based on theoretical project management scheduling methodologies and therefore produce comparable results. The developed theories, based on good project management practice, can influence the various and actual impact that popular CIS have on project duration within multi-project environments.

\section{THEORY AND LITERATURE REVIEW}

A comprehensive review of the available literature and a critical analysis of relevant project management theories are imperative in investigating and understanding the interdependency between the scheduling techniques used by CIS and their contributions to reducing the planned duration of projects within multi-project environments.

Program Evaluation and Review Technique (PERT) is used to estimate project duration when there is a high degree of uncertainty regarding the estimation of the duration of individual activities. Its objective is to predict the end date and not to reduce project duration - a common misconception. Critical Path Method (CPM), concerned with the trade-off between cost and completion dates for projects, predicts project duration by analysing which sequence of activities has the least amount of scheduling flexibility [9]. A common criticism of methods such as PERT is that they do not account for path convergence (also known as merge point bias) and thus tend to underestimate project durations [9]. This aspect is addressed by critical chain scheduling, which aims to develop a sound schedule using buffer management.

In order to shorten project durations, various techniques are used. Fast tracking is a common method to ensure reduction in project duration whilst maintaining quality; however, this method may increase project risk to unacceptable levels [11]. Concurrent engineering, helpful in reducing project duration without necessarily increasing risk, is a design philosophy of cross-functionality cooperation and not the simple overlapping of activities, as with fast tracking. Steyn [11] examines combinations of project management techniques to supplement each other, concluding that an integration of critical path method and critical chain scheduling should lead to a short project duration whilst addressing the risk of not meeting the scheduled due date. 
Most prior studies examine and evaluate project management approaches in single project environments, without thoroughly examining their performance in a multiproject environment. Cohen, Mandelbaum, and Shtub [3] explore critical chain methodology in multi-project organisations, concluding that critical chain offers an intuitive method for planning, scheduling, and controlling multi-project systems. Dass and Steyn [5] explore and evaluate the theory of constraints method for assigning resources and its effect on project duration. Viljoen and Steyn [13] propose an enhancement to Cooper's model (Cooper, Edgett, and Kleinschmidt [4]) and to critical chain project management, through the placement and the management of buffers as an integral part of the pre-project process, in an attempt to provide a mechanism to increase whole system productivity. In the multi-project setting, the availability of prioritisation rules, or heuristics, known to be effective in minimising project duration and maximising resource utilisation, may be of great value. However, difficulty arises in attempting to predict which heuristic procedure will be suitable for any particular situation.

Numerous project management CIS, ranging in sophistication and price, are currently available. CIS address the basic requirements of a project management tool and claim additional functionality, with impressive graphical user interfaces (GUIs). These CIS employ a variety of scheduling techniques, and are rapidly developing and improving with advancements in technology.

\section{RESEARCH DESIGN AND METHODOLOGY}

The research design was an empirical study that evaluated and compared the impacts of popular CIS on reducing project durations in a specific multi-project environment. Three real projects from a financial institution were selected for the experiment. Data gathering was by means of experimental research, conducted in a systematic way, to manipulate the various software-specific scheduling settings in order to observe the resultant effects. The experimentation occurred in a controlled and contemporary setting, and measures to ensure the exclusion of human behaviour received specific attention. Data analysis consisted of classification and correlation analysis.

The research methodology was a five-phase process that included a detailed literature review, the selection and acquisition of three CIS, the selection of projects for experimental purposes, data gathering via controlled experimentation, followed by data analysis and detailed discussion of the results.

\subsection{Research instrumentation}

Student versions of the three CIS to be tested, as listed in Table 1, together with relevant manuals, were sourced and categorised as part of the study. To maintain the academic credibility of this study and to avoid compromising any project management CIS developer, the names of the packages are withheld. Efforts were made to ensure that popular packages - i.e. popular by frequency of use - were selected. However, categorisation is only by retail price of the most basic license for each package, since determining the actual number of users per package and hence its popularity, is beyond the scope of this study. The study acknowledges that personalised computer settings and individual CIS applications may have influenced 
the results. However, the study made every effort to ensure that known default settings were used.

$\begin{array}{lll}\text { Project Management CIS } & \text { Base scheduling methodology } & \text { Price (US \$) } \\ \text { CIS A } & \text { CPM } & 600 \\ \text { CIS B } & \text { Critical chain } & 1,295 \\ \text { CIS C } & \text { CPM, Critical chain } & 1,000\end{array}$

Table 1: CIS evaluated in this study

Three strategic projects were identified and selected that might achieve the specific added benefits resulting from shorter project durations. They are shown in Table 2 Table 3, Table 4 and Table 5 illustrate the activities, durations, predecessors, and resource requirements for projects $A, B$, and $C$ respectively.

$\begin{array}{lll}\text { Project identity } & \text { Priority } & \text { Potential benefit of reduced project duration } \\ \text { Project A } & \text { H1(highest) } & \text { Cost savings } \\ \text { Project B } & \text { H2 } & \text { A window of opportunity } \\ \text { Project C } & \text { H3 } & \text { Cost savings and generation of revenue }\end{array}$

Table 2: List of projects used in this study

\begin{tabular}{|lllll|}
\hline Activity No. & Activities & Duration & Predecessors & Resources \\
\hline 1 & AA1 & 1 & - & R1 \\
\hline 2 & AA2 & 5 & 1 & R1 \\
\hline 3 & AA3 & 1 & 1 & R1 \\
\hline 4 & AA4 & 20 & 1 & R2 \\
\hline 5 & AA5 & 2 & 4 & R4 \\
\hline 6 & AA6 & 5 & 4 & R3 \\
\hline 7 & AA7 & 17 & 5 & R2 \\
\hline 8 & AA8 & 13 & 3 & R7 \\
\hline 9 & AA9 & 10 & 2,3 & R1 \\
\hline 10 & AA10 & 19 & $6,7,8,9$ & R5 \\
\hline 11 & AA11 & 6 & 8 & R2 \\
\hline 12 & AA12 & 5 & 10,11 & R3 \\
\hline 13 & AA13 & 15 & 12 & R2 \\
\hline 14 & AA14 & 5 & 13 & R3 \\
\hline 15 & AA15 & 5 & 14 & R7 \\
\hline 16 & AA16 & 9 & 10 & R6 \\
\hline 17 & AA17 & 12 & 16 & R2 \\
\hline 18 & AA18 & 1 & 15,17 & R1 \\
\hline
\end{tabular}

Table 3: Activities list for Project A 


\begin{tabular}{|c|c|c|c|c|}
\hline Activity No. & Activities & Duration & Predecessors & Resources \\
\hline 1 & $\mathrm{AB1}$ & 1 & - & R1 \\
\hline 2 & $A B 2$ & 5 & 1 & R8 \\
\hline 3 & AB3 & 3 & 1 & R5 \\
\hline 4 & AB4 & 3 & 3 & R5 \\
\hline 5 & AB5 & 1 & 4 & R9 \\
\hline 6 & AB6 & 18 & 3 & R9 \\
\hline 7 & $A B 7$ & 5 & 4,6 & R9 \\
\hline 8 & $A B 8$ & 5 & 7 & R8 \\
\hline 9 & AB9 & 5 & 8 & R9 \\
\hline 10 & $\mathrm{AB} 10$ & 3 & 9,5 & R3 \\
\hline 11 & $\mathrm{AB} 11$ & 1 & 10 & R9 \\
\hline 12 & $\mathrm{AB} 12$ & 23 & 6 & R6 \\
\hline 13 & AB13 & 8 & 2 & R1 \\
\hline 14 & $\mathrm{AB} 14$ & 3 & 13 & R1 \\
\hline 15 & AB15 & 5 & 14 & $\mathrm{R} 1$ \\
\hline 16 & AB16 & 19 & $2,11,12$ & R11 \\
\hline 17 & AB17 & 14 & 16 & $\mathrm{R} 11$ \\
\hline 18 & AB18 & 16 & 16 & R10 \\
\hline 19 & AB19 & 33 & 16 & R3 \\
\hline 20 & AB20 & 7 & $17,18,19$ & R4 \\
\hline 21 & AB21 & 21 & 20,15 & R8 \\
\hline 22 & $\mathrm{AB} 22$ & 1 & 21 & R1 \\
\hline
\end{tabular}

Table 4: Activities list for Project B

\begin{tabular}{|lllll|}
\hline Activity No. & Activities & Duration & Predecessors & Resources \\
\hline 1 & AC1 & 5 & - & R16 \\
\hline 2 & AC2 & 4 & 1 & R16 \\
\hline 3 & AC3 & 4 & 2 & R16 \\
\hline 4 & AC4 & 1 & 3 & R1 \\
\hline 5 & AC5 & 1 & 4 & R12 \\
\hline 6 & AC6 & 5 & 5 & R13 \\
\hline 7 & AC7 & 2 & 4 & R1 \\
8 & AC8 & 3 & 3 & R1 \\
\hline 9 & AC9 & 3 & 6,7 & R14 \\
10 & AC10 & 2 & 4,7 & R4 \\
\hline 11 & AC11 & 1 & 6,8 & R12 \\
12 & AC12 & 18 & 9 & R14 \\
\hline 13 & AC13 & 1 & 12 & R12 \\
\hline 14 & AC14 & 7 & 11,12 & R13 \\
\hline 15 & AC15 & 36 & 10 & R4 \\
16 & AC16 & 3 & 4 & R3 \\
\hline 17 & AC17 & 4 & 14 & R15 \\
18 & AC18 & 9 & 15 & R4 \\
\hline 19 & AC19 & 24 & $13,16,17,18$ & R16 \\
\hline 20 & AC20 & 1 & 19 & R1 \\
\hline
\end{tabular}

Table 5: Activities list for Project C 


\subsection{Experimental design}

The purpose of the experiment was to provide a first-order indication of the merit of the scheduling techniques implemented by each CIS. The three CIS, together with three high priority projects, were the major tools in this experiment. As the objective was to compare only the performance of the three alternative CIS in terms of their ability to reduce project duration, the experiment used deterministic activity durations. The projects, performed by a common pool of resources, included numerous specialist activities, which imply that specific resources were required for specific tasks. In addition, resource allocation and scheduling had to adhere to the stipulated prioritisation rules. The experimental procedure included a repetition of five basic steps for each of the three CIS - i.e., install a student version of the software, schedule projects, record individual and total project durations, identify and manipulate software specific scheduling with the intention of first levelling resources and then obtaining minimum project and total combined durations (shortest period required for all three projects to be completed), and record results. It is important to note that the scheduling of projects and the related resource allocations occurred independently for each CIS. This implies that during the experiment, the CIS installed first did not retain resources as originally allocated, i.e. each CIS is implemented with the original allocation of available resources.

\section{RESULTS}

To draw meaningful comparisons, it is imperative that the evaluations of results are based on common measures. Planned critical chain schedules are comparatively shorter than traditional schedules, since contingency reserves are removed from each activity and aggregated into a project buffer [9]. A mathematical fact is that less reserve is required when aggregated [11]. Due to the fact that no provision is made for contingencies at activity level, the effects of student syndrome may be reduced [11]. However, this study does not attempt to prove the main claims of project management methodologies nor evaluate the effects of human behaviour. Therefore, results of critical chain schedules are not compared with those of traditional CPM. For this reason, comparisons are made between the performances of CIS A and CIS C, as both packages are based on CPM; and the performances of CIS $B$ and CIS C, since these packages allow critical chain scheduling.

\subsection{Comparison of CIS based on CPM schedules (CIS A, CIS C)}

Figure 1 illustrates results obtained from CIS A and CIS C using standard techniques for resolving resource contention. The settings used for the levelling order ignore project and task priorities. CIS C, in comparison to the performance of CIS A, produces a shorter total duration for Project A $(0.79 \%)$ and Project $C(5.26 \%)$ as well as a $0.78 \%$ net reduction in total combined duration.

The difference in impacts of CIS A and CIS C on planned project duration is relatively small, and the question arises whether or not there would be any practical significance. A further question that arises is whether the number of projects or the size of individual project networks may be factors that could increase the percentage reduction. 


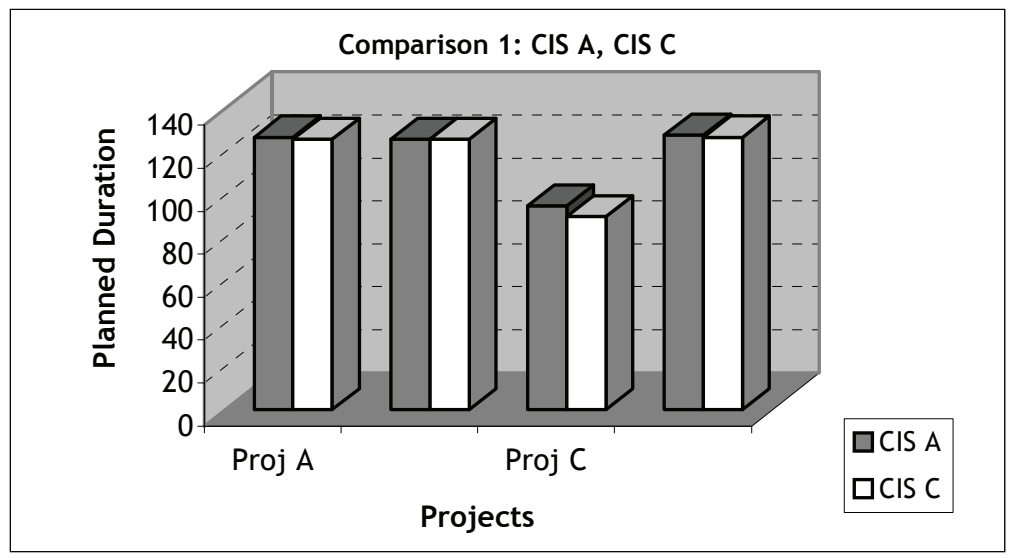

Figure 1: CIS A, CIS C - Comparison 1

Figure 2 shows results obtained from CIS A and CIS C using priority / standard techniques for resolving resource contention. CIS $\mathrm{C}$, in comparison to the performance of CIS A, produces a shorter total duration for Project B (12.41\%) as well as a $12.33 \%$ net reduction in total combined duration. However, CIS A produces a $13.21 \%$ net reduction in Project $A$ and a $3.13 \%$ net reduction in Project $C$.

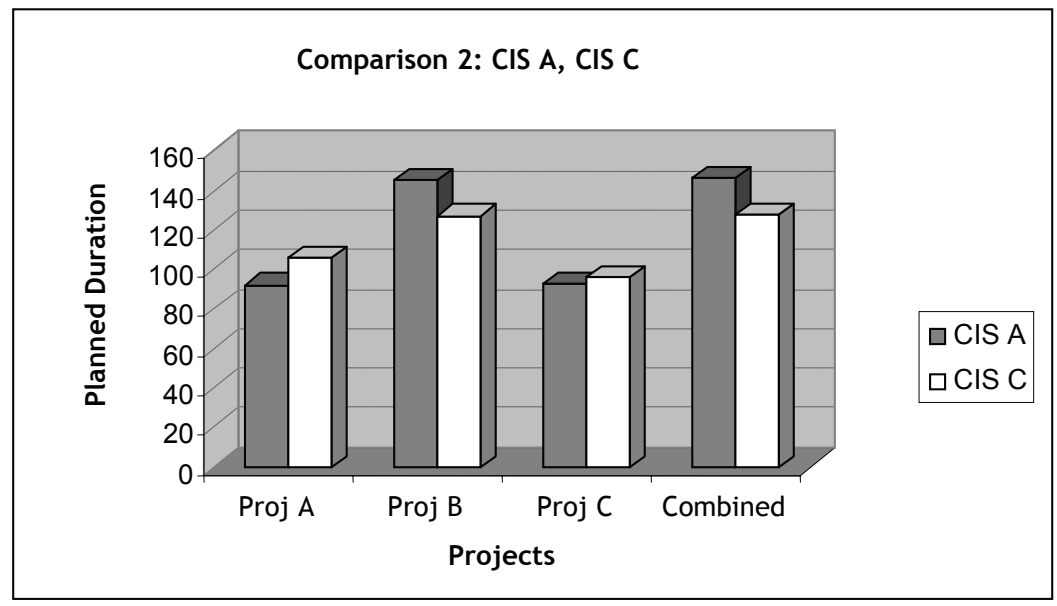

Figure 2: CIS A, CIS C - Comparison 2 
It is evident that the relative influences of the two packages on planned project duration differ substantially in Comparison 2, when applying CIS prioritisation techniques for the resolution of resource contention and critical path scheduling. So it is imperative to understand the scheduling techniques applied by each CIS, with specific reference to prioritisation.

When CIS A undertakes to alleviate resource over-allocation, it goes through a series of decisions about each of the tasks within the schedule in order to determine whether the system can delay specific tasks. In order to determine which tasks can be delayed, CIS A examines the following factors: available slack, task duration, task constraints, task priority, task dependencies, and scheduling dates. There are two types of priorities, task and project, that can be set to control the order in which CIS A levels tasks. Project-level priorities control the levelling of tasks in the project in relation to other projects and tasks in a multiple-project plan.

CIS C first examines the project priority when levelling resources across multiple projects. When automatically levelling resources across multiple projects, tasks in projects having higher priority values maintain their position as long as there are tasks in lower priority projects that the system can delay or split to solve the overallocation of a resource. If the project priorities are equal, CIS C examines the task priority. When automatically levelling resources, tasks having higher priority values maintain their position as long as there are tasks with lower priority values that the system can delay to solve the over-allocation of a resource.

\subsection{Comparison of CIS based on Critical Chain schedules (CIS B, CIS C)}

Figure 3 shows results obtained from CIS B and CIS C using standard techniques for resolving resource contention and scheduling projects by the critical chain method. $\mathrm{CIS} C$, in comparison to the performance of CIS B, produces a shorter total duration for Project A (17.05\%), Project B (32.49\%) and Project C (12.0\%), as well as a $26.26 \%$ net reduction in total combined duration.

The relative influences of both packages on planned project duration differ substantially. It is worthwhile, therefore, to understand the scheduling techniques applied by each CIS, with specific reference to critical chain scheduling.

CIS B uses the 'level load' function to minimise overall start-to-finish duration across all projects. Levelling itself occurs in three independent passes. The task timing constraints attached to each task determine the three passes. CIS B project scheduling does not consider task-timing constraints to be sacred; violation of such constraints occurs if CIS B cannot determine any way to honour them, given existing task and resource dependencies. CIS B determines the project buffer size and feeder buffer sizes as either a fixed duration plus a percentage of the critical chain, or as a fixed duration to be added to the square root of the sum of squares. Resource buffer sizes are set as fixed durations. Consolidated integration risk prevents feeding or pacing resource buffers from pushing the project completion date later when those buffers are inserted into the network. This option does not shorten the project buffer; instead, the project buffers are extended (integration risk) to meet the completion date that would occur without this option. 


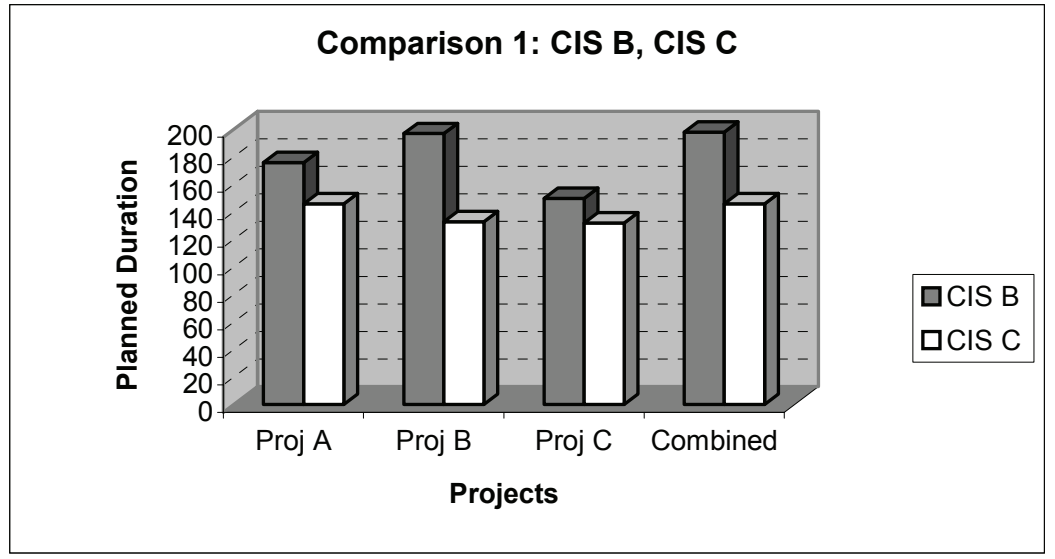

Figure 3: CIS B, CIS C - Comparison 1

In Critical Chain Planning mode, the development of the schedule occurs by defining tasks and allowing CIS C to schedule the project backwards from the target finish date. When adding a task to the project, CIS C places it as late as possible in the schedule. Then, when adding and linking another task appropriately to the first task, CIS C moves the first task backwards in time to make room to complete both the first and second task by the target end date. This process continues until the completion of additions and linkages of all tasks. CIS C automatically resolves resource contention by moving one or more tasks such that the same resource can accomplish them during different periods. CIS C resolves resource contentions backwards in time from the project's target finish date. The identification of Critical Chain tasks is by command or manually via user input. Once identified, critical tasks remain critical and may only change after the manual re-issue of the command. The insertion of buffers of time at key points in the schedule provides the safety net.

In accordance with critical chain (CC) theory, the principle of aggregation and the $50 / 50$ rule, $50 \%$ reduction in planned activity durations should occur and the removed reserve placed into a buffer. Then a further $50 \%$ reduction in the size of the buffer should occur. However, the above technique used by CIS B applies CC scheduling without initially reducing the original activity durations by $50 \%$, resulting in exaggerated project durations. Therefore a manual reduction in the original activity durations is enforced, and the above manipulation of scheduling techniques is re-applied.

Figure 4 shows results obtained from CIS B and CIS C using standard techniques for critical chain application with a manual input of $50 \%$ original task durations. CIS C, in comparison to the performance of CIS B, produces a shorter total duration for Project B (38.71\%) and Project C (11.41\%) as well as a $37.07 \%$ net reduction in total combined duration. However, CIS B produces a shorter duration for Project A (5.5\%) 


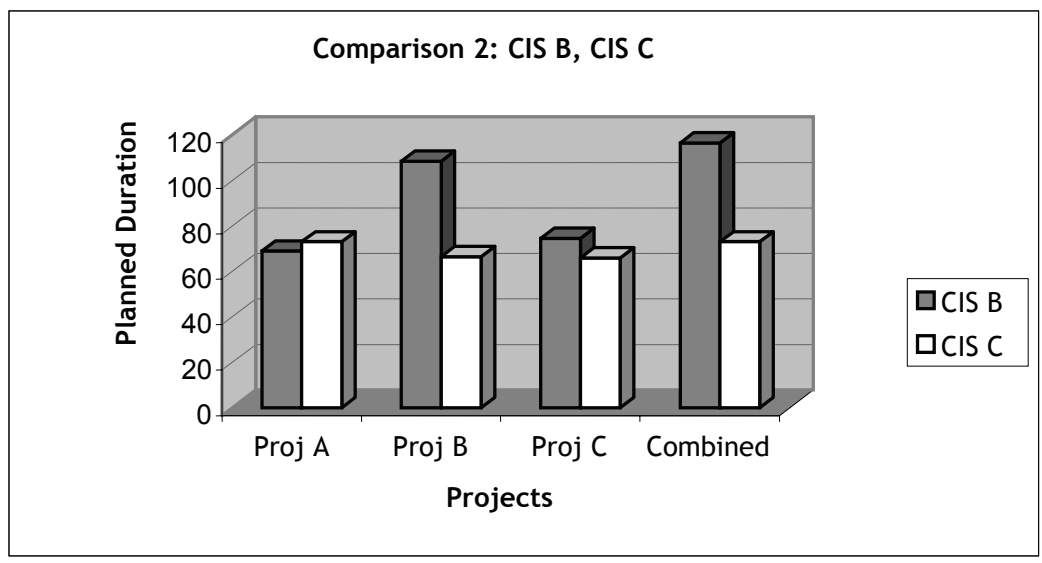

Figure 4: CIS B, CIS C - Comparison 2

The relative influences of both packages on planned project duration differ substantially again in Comparison 2, when applying CIS standard techniques for the resolution of resource contention and project scheduling. This is an expected result, since Comparison 2 applies similar scheduling techniques to those in Comparison 1, with the difference being the manual reduction of original task durations by $50 \%$ for Comparison 2. However, it is evident that the change in individual task duration has had an impact on the percentage reduction of planned project duration.

Figure 5 illustrates the results obtained from CIS B and CIS C using standard techniques for critical chain application, with specific consideration for stipulated priority. CIS C, in comparison to the performance of CIS B, produces a shorter total duration for Project A $(0.71 \%)$, Project B $(17.89 \%)$ and Project $C(5.04 \%)$ as well as an $18.32 \%$ net reduction in total combined duration.

The relative influences of the two packages on planned project duration differ substantially in Comparison 3, when applying CIS prioritisation techniques for the resolution of resource contention and critical chain project scheduling. So it is critical to understand the scheduling techniques applied by each CIS, with specific reference to prioritisation.

CIS B achieves the resolution of resource contention in three independent passes, which allows different priorities for tasks. Task timing constraints attached to each task determine the passes. The separate passes allow extra options for prioritising tasks when scheduling.

CIS C levels resources across multiple projects by eliminating multi-tasking and allocating resources based upon project priority. Tasks in projects having higher priority values maintain their position as long as there are tasks in lower priority projects that the system can delay to solve the over-allocation of a resource. If the project priorities are equal, or if levelling of resources within a single project only, 
CIS C examines the task priority. When automatically levelling resources, tasks having higher priority values maintain their position as long as there are tasks with lower priority values that the system can delay or split to solve the over-allocation of a resource.

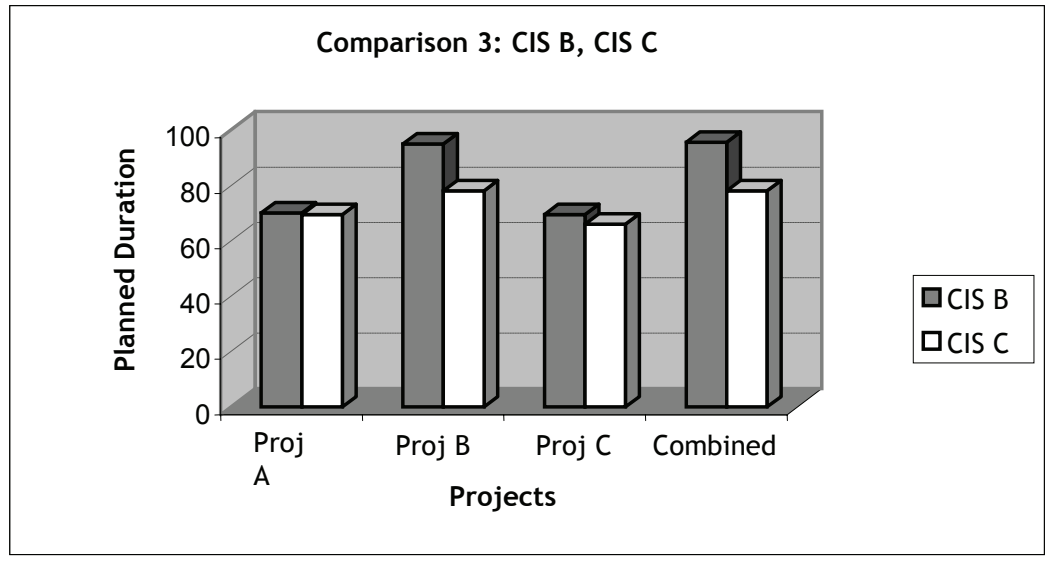

Figure 5: CIS B, CIS C - Comparison 3

\section{CONCLUSIONS AND RECOMMENDATIONS}

Substantial differences were identified when comparing the relative influences of packages on planned project duration. The variation in results is attributed to the scheduling techniques employed, making it imperative to identify the specific scheduling techniques and heuristics that have had the greatest impact. CIS C compared favourably when applying the critical path method with specific consideration for priority. CIS C also compared favourably when applying critical chain scheduling.

The cost of a basic license for the three CIS is in the same order of magnitude. However, because CIS C produces shorter durations in comparison to CIS A, it can be argued that CIS C is more cost effective, as shorter project durations may position an organisation to achieve the benefits described in section 1.2. Similarly, it can be argued that CIS C is more cost effective than CIS B.

A main conclusion is that the three systems, with retail prices of approximately the same order of magnitude, tested with manipulations of their default settings, rendered substantially different project durations. One explanation for the differences is that there is a large number of possible ways to schedule the three projects. If $n$ activities are to be accomplished by $m$ resources, and all activities require all resources, there would be $(n !) m$ possible schedules. Using optimisation to solve the problem of resource allocation requires computing time that increases exponentially with the size of the networks, thereby limiting its application (Tsai and Chiu [12]; Al-jibouri [1]; Chelaka et al. [2], in Dass and Steyn [5]). 
The fact that the CIS render substantially different planned durations provides support for the hypothesis that the scheduling methods employed by the commercially available software systems are neither standardised nor optimised. It is possible that a set of heuristic rules used by one system may outperform another set of heuristics in a particular situation, but may perform adversely in a different situation. It is not yet known which system would perform better in what type of situation, and determining this would require a substantial amount of research.

The study concludes that relationships between the project management computerised information systems used and the planned duration of projects in multi-project environments do exist, and the impact on planned project duration is attributed to the differences in scheduling techniques used by the various computerised information systems.

\subsection{Contributions to theory and practice}

The evaluation and comparison of the impact that the CIS have on the planned duration of projects within a multi-project environment provides a first order indication for organisations of the expected performance and contributions of these systems. Furthermore, such organisations will learn that project durations can vary in accordance with the project-specific software implemented. With respect to the organisation selected for this study, results indicate that CIS C is the preferred system to implement.

The study has highlighted, through experimental procedures, the scheduling techniques and heuristics of CIS C, which had a comparatively positive impact on the reduction of planned project duration in a multi-project environment. Therefore, in practice, specific attention should be given to CIS C prioritisation heuristics and the manner in which CIS C schedules tasks using critical chain project management.

\subsection{Limitations of the study}

The study is limited to 'popular' project management CIS and therefore the investigations are unique and applicable to a limited number of selected CIS. Furthermore, the experimental procedure has shown that a change in individual task duration influences the percentage reduction of planned project duration when applying critical chain scheduling techniques. Another question that arises is whether the number of projects or the size of the individual project networks may be factors that could negatively influence the percentage reduction in planned durations.

\subsection{Recommendations for further research}

The experimental procedure was an exploratory investigation providing a first order indication of the impact that various project management CIS have on planned project duration in multi-project environments. Further research could examine the effects of the number of projects and the complexity of project networks on the percentage reduction in planned durations in similar environments. Such investigations may provide sufficient insight and stimulus for further theoretical research on scheduling techniques. 
The contributions of project management CIS to the successful implementation of projects go beyond reduced project duration. Other requirements that CIS must satisfy include the provision of functionality to identify, plan, analyse, design, implement, and maintain projects. They must cater for predefined goals, using efficient and cost-effective methods, and produce deliverables based on a specific plan. Graphical user interfaces, where users and the application collaborate, and overall user-friendliness, are further characteristics of CIS that are of relative importance to numerous organisations. Another characteristic is user-empowered interfaces that provide users with more control over different aspects of the software. A study exploring which CIS criteria are of relative importance to specific organisations, determined through questionnaires, and an evaluation of CIS based on such criteria, may be of significance to project-driven organisations.

\section{REFERENCES}

[1] Al-jibouri, S. 2002. Effects of resource management regimes on project schedule. International Journal of Project Management, 20(4), 271-277.

[2] Chelaka, M., Abeyasinghe, L., Greenwood, D. J. \& Johansen, D. E. 2001. An efficient method for scheduling construction projects with resource constraints. International Journal of Project Management, 19(1), 29-45.

[3] Cohen, I., Madelbaum, A. \& Shtub, A. 2004. Multi-project scheduling and control: A process-based comparative study of the critical chain methodology and some alternatives. Project Management Journal, 35(2), 39-50.

[4] Cooper, R.G., Edgett, S.J. \& Kleinschmidt, E.J. 2001. Portfolio management. Fundamental to new product success. Working Paper No. 12. Product Development Institute.

[5] Dass, S. \& Steyn, H. 2005. An exploratory assessment of project duration in multiple-project schedules where resources are allocated by the theory of constraints method. Pretoria: University of Pretoria: Department of Engineering and Technology Management.

[6] Fox, T. \& Spence, J. 1998. Tools of the trade: A survey of project management tools. Project Management Journal, 29(3), 20-27.

[7] Jugdev, K. \& Thomas, A. 2002. Project management maturity models: The silver bullets of competitive advantage? Project Management Journal, 33(4).

[8] Levine, H. 2005. Benefits from expediting projects: Expedite your way to lower costs and higher profits. Available from: http://www.sciforma.com. [Accessed 02 June 2006]

[9] Meredith, J. R. \& Mantel, S. J. 2006. Project management - a managerial approach, $6^{\text {th }}$ edition, John Wiley \& Sons, Inc. New York. 
[10] Regnier, E. 2005. Activity completion times in PERT and scheduling network simulation, Part II. Monterey, California: DRMI Newsletter, Defence Resources Management Institute, Naval Postgraduate School.

[11] Steyn, H. 2003. Comparison between and combinations of different approaches to accelerate engineering projects. SA Journal of Industrial Engineering, 14(2).

[12] Tsai, D.M. \& Chiu, H.N. 1996. Two heuristics for scheduling multiple projects with resource constraints. Construction Management and Economics, 14(4), 325-340.

[13] Viljoen, P.J. \& Steyn, H. 2005. A model for increasing productivity of project portfolio delivery systems. Pretoria: University of Pretoria: Department of Engineering and Technology Management. 